\title{
The Ventrolateral Hypothalamic Area and the Parvafox Nucleus: Role in the Expression of (Positive) Emotions?
}

\author{
Gonzalo Alvarez-Bolado ${ }^{1}$ and Marco R. Celio ${ }^{2 *}$ \\ ${ }^{1}$ Department of Neuroanatomy, Institute of Anatomy and Cell Biology, University of Heidelberg, D-69120 Germany \\ ${ }^{2}$ Anatomy and Program in Neuroscience, University of Fribourg, CH-1700 Fribourg, Switzerland
}

\begin{abstract}
The lateral hypothalamus has been long suspected of triggering the expression of positive emotions, because stimulations of its tuberal portion provoke bursts of laughter. Electrophysiological studies in various species have indeed confirmed that the lateral hypothalamus contributes to reward mechanisms. However, only the rudiments of the neural circuit underlying the expression of positive emotions are known. The prefrontal cortex, the lateral hypothalamus, and the periaqueductal gray matter (PAG) are involved in these circuits; so, too, are the brainstem nuclei that control the laryngeal muscles and subserve mimicry, as well as the cardiovascular and respiratory systems. The implicated populations of hypothalamic neurons have not been defined either anatomically or molecularly. One promising candidate is the novel parvafox nucleus, which we recently
\end{abstract}

described, in the murine medial forebrain bundle (mfb), which specifically expresses parvalbumin and Foxb1. With the molecularly defined parvafox nucleus as a centerpiece, the inputs from the prefrontal cortex and the projections to the PAG and brainstem can be studied with precision. By drawing on genetic approaches, it will be possible to manipulate the circuitry selectively with spatial and temporal exactitude and to evaluate the concomitant autonomic changes. These data will serve as a basis for imaging studies in humans using various paradigms to provoke the expression of positive emotions. In conclusion, studies of the hypothalamic parvafox nucleus will reveal whether this entity represents the fulcrum for positive emotions, as is the amygdala for fear and the insula for disgust.

INDEXING TERMS: lateral hypothalamic area; PV1-Foxb1 nucleus; parvafox nucleus; periaqueductal gray (PAG); gelastic seizures; hamartoma; lateral orbital cortex; medial forebrain bundle; lateral tuberal nucleus

\section{WHAT IS THE LATERAL HYPOTHALAMIC AREA AND WHAT QUESTIONS DOES IT PROVOKE?}

The lateral hypothalamic area (LHA) is a brain region without obvious neuronal aggregates; viz., it is reticular in appearance. It occupies the entire length of the hypothalamus, from the preoptic to the mammillary regions, and is traversed by a large axonal tract, the medial forebrain bundle (mfb; for review see Hahn and Swanson, 2010). The LHA can be considered as a continuation of the brainstem reticular system, particularly of the lateral parvocellular reticular formation, which serves as a relay in viscerosensory and visceromotor pathways (Voogd et al., 1998). Mysterious because of its complex reticular structure, the LHA began to attract attention after the discovery therein of melanin- concentrating hormone ( $\mathrm{MCH})$ - and particularly of hypocretin/orexin-expressing neurons (de Lecea et al., 1998; Zamir et al., 1986). With a view to ascribing particular functions to specific neuronal groups within the LHA, it would be of value to identify as many restricted neuronal groups as possible that express specific markers. In an attempt to identify novel LHA entities, we have focused on two discrete, ventrolaterally located neuronal groups that express Foxb1 and parvalbumin (Parv; Alvarez-Bolado et al., 2000; Celio, 1990; Meszar et al., 2012). Together these neurons form a

*CORRESPONDENCE TO: Marco R. Celio, Anatomy and Program in Neuroscience, University of Fribourg, Rte. A. Gockel 1, CH-1700 Fribourg, Switzerland. E-mail: marco.celio@unifr.ch 
novel specific nucleus, which we previously referred as the PV1-Foxb1 nucleus and which we now propose to call the parvafox nucleus. Here, we review the circumstantial evidence pointing to a role of the ventral LHA in the expression of emotions. To this end, we will draw on data that concern the parvafox as an entry point. We will avoid referring to the $\mathrm{MCH}$ - and the hypocretin/orexin-expressing neurons of the dorsal LHA, which have been the subject of recent reviews (see, e.g., Croizier et al., 2013; Giardino and de Lecea, 2014).

In the second section of this article, we attempt to locate the parvafox nucleus with the available Nisslbased maps of the LHA and to discuss what is known about its embryonic development. In the third section, the connections of the parvafox nucleus are discussed in the context of what is known concerning the connections of the LHA generally. In the fourth section, we review recent work on the function of the ventral LHA; in particular the insights that have been gained by analyses of their connections (Goto et al., 2001, 2005; Hahn and Swanson, 2010, 2012), and what can be learnt from the connections of the parvafox nucleus (Bilella et al., 2015; Celio et al., 2013).

The ventral LHA is undoubtedly a very important brain locus, which plays a pivotal role in behavior. Its analysis could have an impact on our understanding of human behavior in health and disease. To carry out this analysis, it is imperative to dissect the structure and the function of the ventral LHA at the molecular level, which would involve monitoring the expression levels of specific genes. This Review ends with an evaluation of the outlook for the methods that are now being used to unravel the function of the ventral LHA and draws attention to the need to identify novel markers in pursuit of this goal.

\section{THE LHA, A RETICULAR REGION WITH FEW SPECIFIC NUCLEI AND MARKERS}

\section{Subdivisions revealed by Nissl staining}

The large extension of the LHA and the perception of its functional importance, together with its apparent lack of neuronal aggregates, have prompted several attempts to subdivide it on the basis of minute structural heterogeneities as revealed by Nissl staining. Working on the rat, the Niewenhuys school (Nieuwenhuys et al., 1982) proposed a complex subdivision of nine lateral and seven medial neuronal aggregates, which can be further subdivided into hundreds of brain loci. Using this nomenclature, which has not found wide acceptance, we have mapped the parvafox nucleus to subnuclei 1 and 2 of the ventrolateral subarea of the LHA (LHVL, 1-2), to parts of the anterolateral subarea of the LHA (LHAL), and to the lateral tuberal nucleus
(TUL; see Fig. 36, levels T10-T11, of Nieuwenhuys et al., 1982). In the third edition of his atlas of the rat brain, Swanson (2004; see also Swanson et al., 2005) used the same method to subdivide the rat LHA into 26 "LHA cell differentiations" or into consistently appearing Nissl-stained groups of cells, which were perhaps insufficiently dense to be recognized as distinct nuclei. The parvafox nucleus can be mapped to three of Swanson's "LHA differentiations," which belong to the lateral tier of the middle group and are referred to as the lateral zone (LHAvl), the parvicellular region (LHApc), and the magnocellular nucleus (LHAm; Swanson, 2004).

We do not know of any systematic attempts to find structure in the LHA of the murine brain, in which it may be smaller and possibly also less well differentiated than in the rat. The canonical murine brain atlas of Paxinos et al. (2009) identifies a number of neuronal nuclei in the LHA without attempting to be exhaustive; several large, reticular areas remain unnamed. The murine parvafox nucleus appears to correspond partially to the paraterete hypothalamic nucleus (PTe) and to be contained within the magnocellular nucleus of the lateral hypothalamus (MCLH; Paxinos et al., 2009). The connections of the Nissl-identified subdivisions have not yet been identified, so we cannot know whether they coincide with those that we have pinpointed (see below). Hence, markers such as parvalbumin and Foxb1 can capture molecular similarities between nerve cells, thereby permitting an identification of functional cell clusters and thus transcending the classical Nissl-based subdivisions (Fig. 1C).

From its topographic location along the optic tract (Gerig and Celio, 2007; Fig. 1A,B) and from the expression of several common genetic markers (Girard et al., 2011; Fig. 1K1-M2), the parvafox nucleus may correspond to the lateral tuberal nucleus (LTN) in humans. Although the LTN is largely ignored in the hypothalamic literature, it is known to be impacted in Huntington's, Pick's, and the argyrophilic grain diseases (Schultz et al., 1998).

\section{Genetic subdivisions (based on gene expression) and emerging markers of the LHA}

As far as we know, only three specific markers label discrete neuronal nuclei within the ventral LHA, Foxb1 and Parv (in the parvafox nucleus; Bilella et al., 2015; Fig. 1C) and calbindin-D28k (Chometton et al., 2015). This last group of neurons is located dorsolateral to the parvafox nucleus and is activated by hedonic food consumption (Chometton et al., 2014).

To give an idea of the possible functional importance of the parvafox, let us emphasize that the number of 
neurons expressing Foxb1 and/or Parv in this structure is twofold greater than the number of hypocretin/ orexin-expressing cells in the dorsal LHA (Bilella et al., 2015). Furthermore, potentially interesting markers have been detected in transcriptomic studies with the Allen Brain Atlas (Girard et al., 2011) and gene array technologies (Albisetti et al., 2015). Some of these markers are expressed in numerous hypothalamic cells, in both the medial and the ventrolateral portions (e.g., Adcyap). Some of the tagged cells form aggregates in the LHA (Tac1, Cart, Penk1, and PDyn), and others colocalize with Parv-expressing neurons in the parvafox nucleus (Adcyap, SPP1, Fig. 1K1-M2; Adan et al., 2006; Foo et al., 2008; Girard et al., 2011, 2015). Moreover, as has been revealed by the expression of the three glycine receptors (GIra1, GIra2, and GIra3; Albisetti et al., 2015), the parvafox nucleus is under the influence of strong glycinergic inhibition.

\section{The parvafox nucleus}

The parvafox nucleus constitutes a wellcircumscribed portion of the ventral LHA. It is subject to the general hypothalamic organization of inputs that derive from the prefrontal cortex (Fig. 1E-I) and that are relayed to lower levels, particularly to the PAG (Fig. 1D1,2) and the brainstem. There are many publications dealing with this type of organization, but in the case of the parvafox nucleus the peculiarity consists of the fact that the inputs derive from the latero-orbital prefrontal cortex (Babalian et al., 2015), a less well-studied cortical region, which may correspond to the area $13 \mathrm{~m} / \mathrm{l}$ in monkeys (Price, 2007).

The parvafox nucleus is a longitudinally oriented tubular structure (Fig. 1A, B) and consists of two coaxially organized cell populations; the core is composed of Parv-positive neurons and the shell of Foxb1expressing neurons, and $10 \%$ of the neurons in the transitional zone express both markers (Bilella et al., 2014; Fig. 1C). The dendrites of these neurons are oriented mainly perpendicular to the axons of the $\mathrm{mfb}$ (Meszar et al., 2012) and are organized according to the "stacked-chips" architectonic principle, which is characteristic of the reticular formation (Szentagothai, 1983).

The longitudinal orientation of the two cell groups is perhaps determined by the caudal-to-rostral (viz. tangential) streaming of the Foxb1-expressing neurons, which originate from the mammillary ventricular wall during the early stages of development (Alvarez-Bolado et al., 2000). This migration is at variance with the three-wave model for hypothalamic development (Altman and Bayer, 1986), which is based on the ${ }^{3} \mathrm{H}$ thymidine-based determination of neuronal birth dates in the rat brain. According to this model, the entire hypothalamus is formed during three "waves" of neurogenesis. These waves generate young neurons, which migrate mediolaterally (i.e., radially) and appose themselves to the previously generated ones (outside-in sequence). In this way, the neurons generated during the first wave would form the lateral hypothalamus; those during the second wave would give rise to an intermediate hypothalamic layer containing large, recognizable nuclei (ventromedial and dorsomedial); and those during the third wave would give rise to the periventricular (viz., the most medial) hypothalamus. Although in very general terms this might be correct, other approaches indicate that the three waves overlap to a high degree, such that LHA cells are generated also at relatively late stages of development (AlvarezBolado et al., 2012). Neurons of the parvafox nucleus migrate mostly tangentially, instead of radially as is classically assumed. Other authors who have focused on the development of identifiable hypothalamic neuronal groups have also reported noncanonical tangential migrations (see, e.g., Diaz et al., 2014; Markakis and Swanson, 1997) as well as the genesis of lateral hypothalamic neurons at relatively late stages of development (Amiot et al., 2005; Brischoux et al., 2001).

\section{EMERGING CONNECTIONAL STRUCTURE OF THE VENTRAL LHA}

A classical insight into brain histology proclaims that brain nuclei (as opposed to homogeneous, "reticular" regions) appear during evolution whenever neurons are "monopolized by specific functions and connections" (Ramon-Moliner and Nauta, 1966). According to this view, the reticular formation (of which the LHA is considered to constitute the rostral portion) has remained relatively undifferentiated and is responsible for the processing of afferent signals of very heterogeneous origins (Ramon-Moliner and Nauta, 1966). This circumstance prompts the question: are there diffuse connections within the ventral LHA that justify it remaining as a "reticular," nonnuclear portion of the CNS? Several recent studies have aimed to map comprehensively the projections from some of Swanson's "LHA cell differentiations" (Goto et al., 2001, 2005; Hahn and Swanson, 2010,2012 ). They have revealed the connections (afferent and efferent) to be paradoxical, viz., at the same time promiscuous and specific: although each "LHA differentiation" connects to a large variety of brain subdivisions (promiscuity), its pattern varies (specificity). This does not belie but refines the dictum of Ramon-Moliner and Nauta (1996; see above). Every histologically recognizable subdivision of the LHA that has been investigated (Goto et al., 2001, 2005; Hahn and Swanson, 2010, 

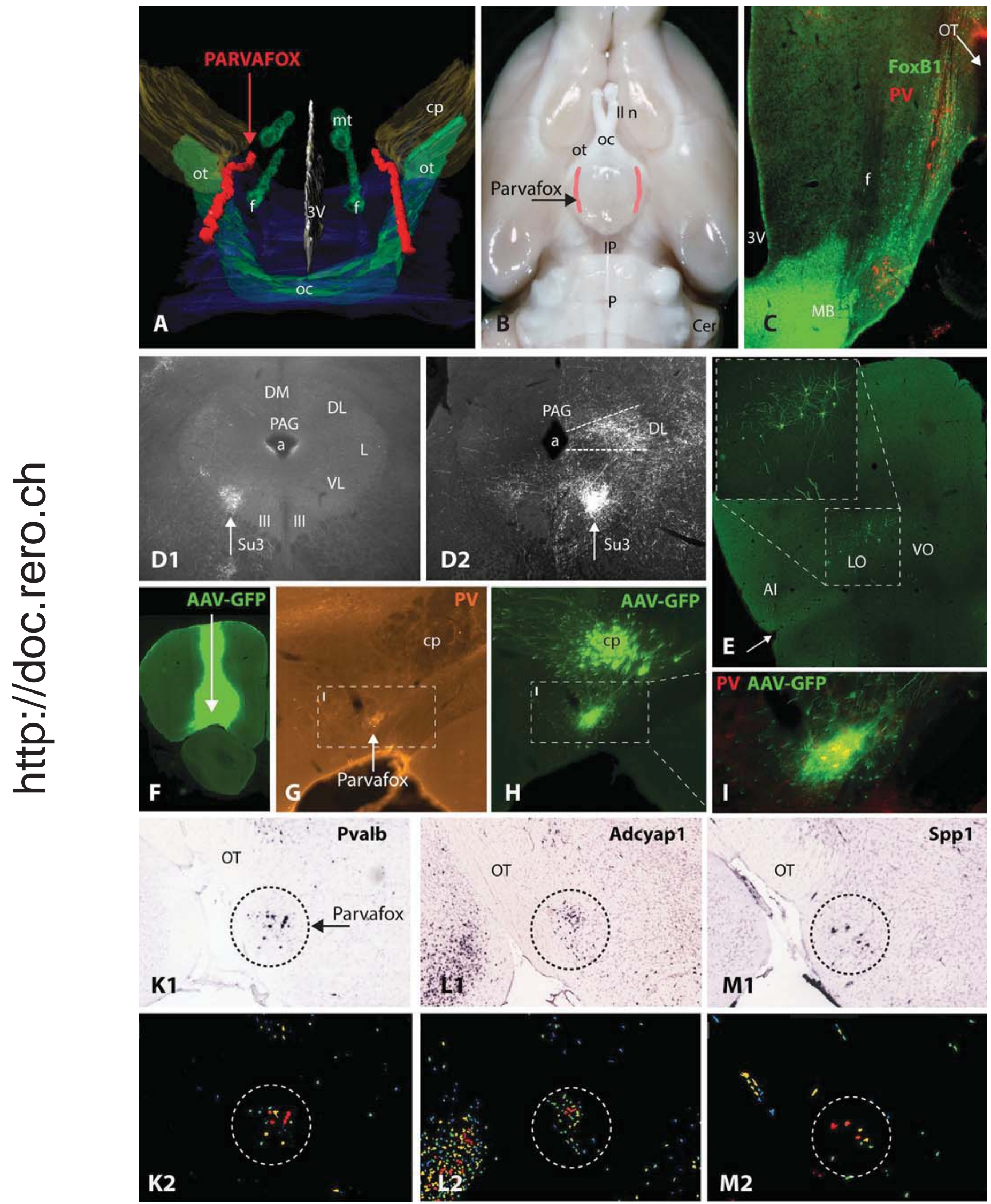

Figure 1. 
2012) projects to a very large number of nuclei (which indicates a lack of specialization), and yet differently. In this way, the LHA operates not as a giant nucleus but as a large set of widely but differentially connected neuronal aggregates. The authors (Hahn and Swanson, 2010) infer from this pattern an "integrative role" for the LHA in the "orchestrated modulation" of behavior.

In the mouse, the connections of the ventral LHA are complex and can be inferred by consulting the spatial search software of the murine connectivity atlas of the Allan Database (http://connectivity.brain-map.org/projection), by monitoring the retrograde transport of the rabies virus from the parvafox nucleus (Szabolcsi et al., 2015; Fig. 1E), or by following the destinies of stereotactic injections of Cre-dependent viral constructs at specific sites in the brains of Pvalb-Cre and Foxb1-Cre mice (Fig. 1F-I). Approximately 60 inputs that may target various portions of the parvafox nucleus can be deduced from these combined studies. One input stands out, namely, that stemming from pyramidal cells in layer $\mathrm{V}$ (Fig. 1E) of the LO-prefrontal cortex, which delivers collaterals to the parvafox nucleus (Babalian et al., 2015). This projection continues to the ventrolateral PAG (and to the brain stem), where it intermingles with the terminals deriving from the parvalbumin-positive subpopulation of neurons in the parvafox nucleus, the latter being presynaptic to the former (Babalian et al., 2015). The parvafox nucleus thus appears to integrate inputs from more than 60 sources and to influence the delivery of the prefrontal information to the PAG (Babalian et al., 2015).

Although the parvafox nucleus receives afferents from numerous brain regions (Szabolcsi et al., 2015), its projections preferentially target the PAG (Fig. 1D1,2), the surrounding midbrain nuclei, and the reticular formation of the brainstem; only limited numbers extend to rostrally situated brain sites (Bilella et al., 2015; Celio et al., 2013). Thus, the parvafox nucleus acquires information from a large variety of brain sites and channels it particularly to the PAG, a brain region responsible for "coordinating distinct strategies for coping with different sets of environmental demands" (Bandler and Shipley, 1994). A similar strong projection to the PAG has been shown for the juxtadorsomedial "LHA differentiation" (Hahn and Swanson, 2012) but not for the juxtaparaventricular one (Hahn and Swanson, 2010). The Parv-positive "core" neurons target the Su3, a restricted columnar region in the ventrolateral part, at the edge of the PAG (Celio et al., 2013; Fig. 1D1). The Foxb1-expressing "shell" additionally projects to the dorsolateral quadrant of the PAG and to the cuneiform nucleus (Bilella et al., 2015; Fig. 1D2). That the core neurons of the parvafox nucleus project to the ventrolateral quadrant of the PAG, and those of the Foxb1expressing shell to the dorsolateral one, is suggestive of a functional corollary. The circumstance implies that the two coaxially organized cell groups play distinct, and perhaps even contrasting, roles in the expression of the autonomic concomitants of emotions.

\section{ROLE OF THE VENTRAL LHA IN POSITIVE EMOTIONS}

Has the ventral LHA, and in particular the parvafox nucleus, anything to do with positive emotions that

Figure 1. Illustrations exemplifying the results of various studies on the parvafox nucleus. A: Schematic reconstruction of the chain of parvalbumin-immunoreactive neurons in the ventral LHA (red), revealing its topographic relationship to the fornix (f) and the optic tract (ot), $3 \mathrm{~V}$, third ventricle; $\mathrm{cp}$, cerebral peduncle; oc: optic chiasm; mt, mammillothalamic tract (reproduced from Meszar et al., 2012). B: Projection of the parvafox nucleus onto the inferior surface of a rat brain. IIn, optic nerve; IP, interpeduncular region; P, pons; cer, cerebellum (reproduced from Celio et al., 2013). C: Image of a horizontal section through the murine hypothalamus after immunostaining for parvalbumin (red) and Foxb1 (green). The parvalbumin-immunoreactive neurons form the core of a cylinder, which is mantled by Foxb1-positive ones. MB, mammillary nuclei (reproduced from Bilella et al., 2014). D1,2: Projections from the parvalbumin-positive (D1) and the Foxb1-positive (D2) subpopulations of neurons in the parvafox nucleus to the periaqueductal gray matter (PAG). The parvalbumin-positive terminals are confined to the Su3 region, which is located at the edge of the PAG, ventral to the aqueduct. The Foxb1-positive projections target primarily the Su3 but extend also to the lateral and the dorsolateral quadrants (reproduced from Bilella et al., 2015). E: Retrograde transport of the rabies virus after the targeted injection of a Cre-dependent construct into the parvafox nucleus of $P V$-Cre mice. A group of retrogradely labeled pyramidal neurons is located in layer V of the LO region of the prefrontal cortex. Arrow points to the rhinal fissure. Al, agranular insular cortex; VO, ventral orbital cortex (reproduced from Szabolcsi et al., 2015). F: Image of a section through the rat brain, taken after the injection of an AAVGFP construct into the LO region of the prefrontal cortex. Arrow indicates the trajectory of the needle. G: Immunostaining for parvalbumin on a section through the rat hypothalamus taken after the injection of an AAV-GFP constructs in the LO-cortex (shown in F). The parvafox nucleus is indicated with an arrow. The boxed region is represented at higher magnification in I. H: The same section as in G, but viewed with another filter set to show the transported AVV-GFP construct. The axons exit the cerebral peduncle (cp) and converge around the neurons of the parvafox nucleus. The boxed region is represented at higher magnification in I. I: Merged images of the boxed regions in $\mathrm{G}$ and $\mathrm{H}$. The parvalbumin- and the Foxb1-positive neurons (the latter not shown) receive strong inputs from the LO. K1-M2: In situ hybridization for Pvalb (K1,2), Adcyap1 (L1,2), and Spp1 (M1,2) reproduced from the Allen database (www.brain-map.org). Images in the upper row $(\mathrm{K} 1, \mathrm{~L} 1, \mathrm{M} 1)$ represent brightfield views, and those in the lower row are the pseudocolor expression profiles. Both Adcyap1 and Spp1 are expressed in neurons of the parvafox nucleus and even coexist with Pvalb in the same cells (modified from Girard et al., 2011). 
justify it being reviewed here? A wealth of neurological data suggests that in humans the hypothalamus triggers laughter (Davison and Kelman, 1939; Martin, 1950a). Benign tumors (hamartomas) developing in the tuberal part of the hypothalamus of children often lead to gelastic (laughing) seizures (Maixner, 2006); so, too, do vascular pathologies, such as aneurysms and bleeding within Willis' circle (Martin, 1950b).

Local electrical stimulation of the rodent $\mathrm{mfb}$ in the ventral LHA (Olds and Fobes, 1981) disengages selfstimulation, thereby affording indirect evidence of a rewarding, pleasurable effect. In rodents, activation of this reward system leads to the production of characteristic ultrasonic vocalizations (USVs) in the form of high-frequency $(50-\mathrm{kHz})$ tones ("chirps"), which have been equated to bursts of laughter in humans (Panksepp and Burgdorf, 2003). In humans, a similar positive state has been evoked from the $\mathrm{mfb}$ (Bishop et al., 1963; Coenen et al., 2011; Heath, 1963). The feeling is one of eager anticipation, enthusiasm, and euphoria (Burgdorf et al., 2011). Traditionally, self-stimulation has been attributed substantially to an activation of the ascending dopaminergic system, although an involvement in this phenomenon of neurons embedded within axons of the mfb has long been suspected (Olds and Olds, 1969). Finally, electrical and chemical stimulation of the ventrolateral hypothalamus gives rise to changes in blood pressure, which range from depression to elevation depending on the rostrocaudal localization (Hess, 1981; Spencer et al, 1989).

Modern brain imaging studies with $\mathrm{fMRI}$ indicate that the viewing of comical cartoons (Schwartz et al., 2008; Watson et al., 2007) and the laughter evoked by tickling (Wattendorf et al., 2012, 2013) activate the LHA. This region is also engaged in the feeling phase of positive emotions, as has been revealed by positron emission tomography (PET), which is considered to be a better technique for imaging slow-time-course affective processes (Damasio et al., 2000). However, the resolution of the images in these fRMI and PET studies is too low to permit an exact correlation with the ventrolaterally located lateral tuberal nucleus, the putative human homologue of the rodent parvafox nucleus. Circumstantial evidence thus confirms the importance of the ventral LHA in vocalization and in the autonomic (e.g., cardiovascular) concomitants of emotions.

\section{APPROACHES AND OUTLOOK}

\section{Methodological problems posed by the reticular nature of the LHA}

The LHA is a "reticular zone" without clear nuclear boundaries; the identification of three chemically speci- fied cell groups (Calb-, Foxb1-, and Parv-positive) and their connections, as revealed by the recent publications cited above, in the ventral LHA ushers in a new era in the analysis of its structure and functions. With the two markers Parv and Foxb1, an unsuspected degree of anatomical and functional organization has been revealed in this particular region, as evidenced by the identification of longitudinal columns of afferent inputs, output neurons, and perhaps even intrinsic interneurons. The complexity of the reticular anatomy of the lateral hypothalamus in general and of the ventral LHA in particular calls for the identification and implementation of novel markers.

\section{Possible experimental paradigms}

The implementation of novel and existing markers would permit a selective molecular tracing with Credependent viral constructs, the targeted activation of subsets of nerve cells with opto- and chemogenetic methods, and even the generation and study of conditional knockout phenotypes. With opto- and chemogenetic techniques, the parvafox nucleus could be artificially stimulated (or inhibited) to observe the behavioral responses. We anticipate that ultrasonic vocalization (50-kHz "chirps") would be affected; changes in blood pressure, in heart rate, and in the threshold to pain, as well as the response to tickling would also be expected. In considering such experiments, investigators should recognize that the ultrasonic vocalizations of mice are typically more complex and variable than those of rats, which renders them less attractive as a model for a functional analysis of how positive and negative affects are organized in the brain. To afford further evidence of putative homology and to identify new neuromodulators that are used by neurons of the murine parvafox nucleus and of the primate LTN, a transcriptomic comparison between the two would be useful.

High-resolution FMRI and functional PET studies in humans are required to elucidate the role of the ventral LHA in the hierarchy of sites implicated in the expression of positive emotions. Human data will permit an accurate pinpointing of the location of the intrahypothalamic activity that is triggered (e.g., during ticklish laughter) and a correlation of these findings with responses of the autonomic nervous system (e.g., changes in skin conductance, heart rate, blood pressure, and tear production).

\section{Outlook}

If the rodent parvafox nucleus and the primate LTN are indeed found to influence the expression (e.g., laughter) and autonomic manifestation (e.g., changes in 
blood pressure and pain sensitivity) of positive emotions, then the discovery could be of importance in understanding the circuitry of positive moods. If the rodent parvafox nucleus proves to be a homologue of the human LTN, then activation studies in an appropriate animal model could reveal whether deep-brain stimulation (DBS) of the LTN would be feasible in certain clinical situations, as has already been found with DBS of the mfb in humans (Schlaepfer et al., 2013). Furthermore, the search for neuropeptides that are preferentially expressed in this circuitry could lead to the discovery of compounds that might be administered to correct an imbalance between negative and positive emotions in patients with mood disorders.

\section{ACKNOWLEDGMENTS}

We thank Alexandre Babalian, PhD, Franck Girard, PhD, Viktoria Szabolcsi, MD, and Alessandro Bilella, PhD student, for providing unpublished figures for the illustration.

\section{ROLE OF AUTHORS}

$\mathrm{GAB}$ and MRC wrote the review together.

\section{CONFLICT OF INTEREST STATEMENT}

No conflicts of interest exist.

\section{LITERATURE CITED}

Adan RA, Tiesjema B, Hillebrand JJ, la Fleur SE, Kas MJ, de Krom M. 2006. The MC4 receptor and control of appetite. Br J Pharmacol 149:815-827.

Albisetti G, Szabolcsi V, Celio MR. 2015. Evidence for glycinergic neurotransmission in the rodent's hypothalamic PV1-Foxb1 nucleus. In preparation.

Altman J, Bayer SA. 1986. The development of the rat hypothalamus. Adv Anat Embryol Cell Biol 100:1-178.

Alvarez-Bolado G, Zhou X, Cecconi F, Gruss P. 2000. Expression of Foxb1 reveals two strategies for the formation of nuclei in the developing ventral diencephalon. Dev Neurosci 22:197-206.

Alvarez-Bolado G, Paul FA, Blaess S. 2012. Sonic hedgehog lineage in the mouse hypothalamus: from progenitor domains to hypothalamic regions. Neural Dev 7:4.

Amiot C, Brischoux F, Colard C, La Roche A, Fellmann D, Risold PY. 2005. Hypocretin/orexin-containing neurons are produced in one sharp peak in the developing ventral diencephalon. Eur J Neurosci 22:531-534.

Babalian A, Eichenberger S, Bilella A, Celio MR. 2015. The lateral orbital prefrontal cortex projects to the PV1Foxb1-nucleus of the ventrolateral hypothalamus. In preparation.

Bandler R, Shipley MT. 1994. Columnar organization in the midbrain periaqueductal gray: modules for emotional expression? Trends Neurosci 17:379-389.

Bilella A, Alvarez-Bolado G, Celio MR. 2014. Coaxiality of Foxb1- and parvalbumin-expressing neurons in the lateral hypothalamic PV1-nucleus. Neurosci Lett 566:111-114.

Bilella A, Alvarez-Bolado G, Celio MR. 2015. The Foxb1expressing neurons of the ventrolateral hypothalamic PV1/Foxb1-nucleus project to regions involved in the defense reaction. In preparation.
Bishop MP, Elder ST, Heath RG. 1963. Intracranial selfstimulation in man. Science 140:394-396.

Brischoux F, Fellmann D, Risold PY. 2001. Ontogenetic development of the diencephalic $\mathrm{MCH}$ neurons: a hypothalamic "MCH area" hypothesis. Eur J Neurosci 13:1733-1744.

Burgdorf J, Panksepp J, Moskal JR. 2011. Frequency-modulated $50 \mathrm{kHz}$ ultrasonic vocalizations: a tool for uncovering the molecular substrates of positive affect. Neurosci Biobehav Rev 35:1831-1836.

Celio MR. 1990. Calbindin D-28k and parvalbumin in the rat nervous system. Neuroscience 35:375-475.

Celio MR, Babalian A, Ha OH, Eichenberger S, Clement L, Marti C, Saper CB. 2013. Efferent connections of the parvalbumin-positive (PV1) nucleus in the lateral hypothalamus of rodents. J Comp Neurol 521:31333153.

Chometton S, Franchi G, Houdayer C, Poncet F, Mariot, A., Fellmann D, Risold PY. 2014. A lateral posterior hypothalamic region involved in hedonic aspect of food consumption. Milan: FENS.

Chometton S, Pedron S, Peterschmitt Y, Van Waes V, Fellmann D, Risold PY. 2015. A premammillary lateral hypothalamic nuclear complex responds to hedonic but not aversive tastes in the male rat. Brain Struct Funct Apr 12.

Coenen VA, Schlaepfer TE, Maedler B, Panksepp J. 2011. Cross-species affective functions of the medial forebrain bundle-implications for the treatment of affective pain and depression in humans. Neurosci Biobehav Rev 35: 1971- 1981.

Croizier S, Cardot J, Brischoux F, Fellmann D, Griffond B, Risold PY. 2013. The vertebrate diencephalic MCH system: a versatile neuronal population in an evolving brain. Front Neuroendocrinol 34:65-87.

Damasio AR, Grabowski TJ, Bechara A, Damasio H, Ponto LL, Parvizi J, Hichwa RD. 2000. Subcortical and cortical brain activity during the feeling of self-generated emotions. Nat Neurosci 3:1049-1056.

Davison C, Kelman H. 1939. Pathologic laughter and crying. Arch Neurol Psych 42:595-643.

de Lecea L, Kilduff TS, Peyron C, Gao X, Foye PE, Danielson PE, Fukuhara C, Battenberg EL, Gautvik VT, Bartlett FS 2nd, Frankel WN, van den Pol AN, Bloom FE, Gautvik KM, Sutcliffe JG. 1998. The hypocretins: hypothalamusspecific peptides with neuroexcitatory activity. Proc Natl Acad Sci U S A 95:322-327.

Diaz C, Morales-Delgado N, Puelles L. 2014. Ontogenesis of peptidergic neurons within the genoarchitectonic map of the mouse hypothalamus. Front Neuroanat 8: 162.

Foo KS, Brismar H, Broberger C. 2008. Distribution and neuropeptide coexistence of nucleobindin-2 mRNA/nesfatinlike immunoreactivity in the rat CNS. Neuroscience 156: 563-579.

Gerig AT, Celio MR. 2007. The human lateral tuberal nucleus: immunohistochemical characterization and analogy to the rodent PV1-nucleus. Brain Res 1139:110-116.

Giardino WJ, de Lecea L. 2014. Hypocretin (orexin) neuromodulation of stress and reward pathways. Curr Opin Neurobiol 29:103-108.

Girard F, Meszar Z, Marti C, Davis FP, Celio M. 2011. Gene expression analysis in the parvalbumin-immunoreactive PV1 nucleus of the mouse lateral hypothalamus. Eur J Neurosci 34:1934-1943.

Goto M, Swanson LW, Canteras NS. 2001. Connections of the nucleus incertus. J Comp Neurol 438:86-122.

Goto M, Canteras NS, Burns G, Swanson LW. 2005. Projections from the subfornical region of the lateral hypothalamic area. J Comp Neurol 493:412-438. 
Hahn JD, Swanson LW. 2010. Distinct patterns of neuronal inputs and outputs of the juxtaparaventricular and suprafornical regions of the lateral hypothalamic area in the male rat. Brain Res Rev 64:14-103.

Hahn JD, Swanson LW. 2012. Connections of the lateral hypothalamic area juxtadorsomedial region in the male rat. J Comp Neurol 520:1831-1890.

Heath RG. 1963. Electrical Self-Stimulation of the Brain in Man. Am J Psychiatry 120:571-577.

Hess WR. 1981. Biological order and brain organization. Berlin: Springer-Verlag.

Maixner W. 2006. Hypothalamic hamartomas-clinical, neuropathological and surgical aspects. Childs Nerv Syst 22: 867-873

Markakis EA, Swanson LW. 1997. Spatiotemporal patterns of secretomotor neuron generation in the parvicellular neuroendocrine system. Brain Res Brain Res Rev 24: 255-291.

Martin JP. 1950b. Fits of laughter (sham mirth) in organic cerebral disease. Brain 73:453-464.

Meszar Z, Girard F, Saper CB, Celio MR. 2012. The lateral hypothalamic parvalbumin-immunoreactive (PV1) nucleus in rodents. J Comp Neurol 520:798-815.

Nieuwenhuys R, Geeraedts LM, Veening JG. 1982. The medial forebrain bundle of the rat. I. General introduction. J Comp Neurol 206:49-81.

Olds ME, Fobes JL. 1981. The central basis of motivation: intracranial self-stimulation studies. Annu Rev Psychol 32:523-574.

Olds ME, Olds J. 1969. Effects of lesions in medial forebrain bundle on self-stimulation behavior. Am J Physiol 217: 1253-1264.

Panksepp J, Burgdorf J. 2003. "Laughing" rats and the evolutionary antecedents of human joy? Physiol Behav 79: 533-547.

Paxinos G, Watson D, Carrive P, Kircailde M, Ashwell KWS. 2009. Chemoarchitectonic atlas of the rat brain. Amsterdam: Elsevier.

Price JL. 2007. Definition of the orbital cortex in relation to speicific connections with limbic and visceral structures and other cortical regions. Ann N Y Acad Sci 1121:54-71.

Ramon-Moliner E, Nauta WJ. 1966. The isodendritic core of the brain stem. J Comp Neurol 126:311-335.
Schlaepfer TE, Bewernick BH, Kayser S, Madler B, Coenen VA. 2013. Rapid effects of deep brain stimulation for treatment-resistant major depression. Biol Psychiatry 73: 1204-1212.

Schultz C, Koppers D, Sassin I, Braak E, Braak H. 1998. Cytoskeletal alterations in the human tuberal hypothalamus related to argyrophilic grain disease. Acta Neuropathol 96:596-602.

Schwartz S, Ponz A, Poryazova R, Werth E, Boesiger P, Khatami R, Bassetti CL. 2008. Abnormal activity in hypothalamus and amygdala during humour processing in human narcolepsy with cataplexy. Brain 131:514-522.

Spencer SE, Sawyer WB, Loewy AD. 1989. Cardiovascular effects produced by L-glutamate stimulation of the lateral hypothalamic area. Am J Physiol 257:H540-H552.

Swanson LW. 2004. Brain maps: structure of the rat brain. New York: Elsevier.

Swanson LW, Sanchez-Watts G, Watts AG. 2005. Comparison of melanin-concentrating hormone and hypocretin/ orexin mRNA expression patterns in a new parceling scheme of the lateral hypothalamic zone. Neurosci Lett 387:80-84.

Szabolcsi V, Babalian A, Bilella A, Celio MR. 2015. Brain wide mapping of inputs to the PV1-Foxb1 nucleus of the hypothalamus. In preparation.

Szentagothai J. 1983. The modular architectonic principle of neural centers. Rev Physiol Biochem Pharmacol 98: 11-61.

Voogd J, Nieuwenhuys R, Van Dongen PAM, Ten Donkelaar HJ. 1998. Mammals. In: Nieuwenhuys R, Ten Donkelaar $\mathrm{HJ}$, Nicholson C, editors. The central nervous system of vertebrates. Berlin: Springer. p 11637-12097.

Watson KK, Matthews BJ, Allman JM. 2007. Brain activation during sight gags and language-dependent humor. Cereb Cortex 17:314-324.

Wattendorf E, Westermann B, Fiedler K, Kaza E, Lotze M, Celio MR. 2013. Exploration of the neural correlates of ticklish laughter by functional magnetic resonance imaging. Cereb Cortex 23:1280-1289.

Zamir N, Skofitsch G, Jacobowitz DM. 1986. Distribution of immunoreactive melanin-concentrating hormone in the central nervous system of the rat. Brain Res 373: 240-245. 